\title{
Acetylcholine boosts dendritic NMDA spikes in a CA3 pyramidal neuron model
}

Rachel Humphries ${ }^{1,2}$, Jack R. Mellor ${ }^{1}$ and Cian O’Donnell ${ }^{2}$

${ }^{1}$ Center for Synaptic Plasticity, School of Physiology, Pharmacology and Neuroscience, University of Bristol, University Walk, Bristol BS8 1TD, UK

${ }^{2}$ Computational Neuroscience Unit, School of Computer Science, Electrical and Electronic Engineering, and Engineering Mathematics, University of Bristol, Bristol BS8 1UB, UK

Correspondence: cian.odonnell@bristol.ac.uk

\section{Highlights}

- Using biophysical computational models of CA3 pyramidal neurons we estimated the quantitative effects of acetylcholine on nonlinear synaptic integration.

- Nonlinear NMDA spikes can be triggered by fewer synapses in distal dendrites due to increased local input resistance.

- Acetylcholine broadly reduces the number of synapses needed to trigger NMDA spikes, but the magnitude of the effect varies across dendrite branches within a single neuron.

- No single potassium channel type is the dominant mediator of the excitability effects of acetylcholine. 


\begin{abstract}
Acetylcholine has been proposed to facilitate the formation of memory ensembles within the hippocampal CA3 network, by enhancing plasticity at CA3-CA3 recurrent synapses. Regenerative NMDA receptor (NMDAR) activation in CA3 neuron dendrites (NMDA spikes) increase synaptic $\mathrm{Ca}^{2+}$ influx and can trigger this synaptic plasticity. Acetylcholine inhibits potassium channels which enhances dendritic excitability and therefore could facilitate NMDA spike generation. Here, we investigate NMDAR-mediated nonlinear synaptic integration in stratum radiatum (SR) and stratum lacunosum moleculare (SLM) dendrites in a reconstructed CA3 neuron computational model and study the effect of acetylcholine on this nonlinearity. We found that distal SLM dendrites, with a higher input resistance, had a lower threshold for NMDA spike generation compared to SR dendrites. Simulating acetylcholine by blocking potassium channels (M-type, A-type, $\mathrm{Ca}^{2+}$-activated, and inwardly-rectifying) increased dendritic excitability and reduced the number of synapses required to generate NMDA spikes, particularly in the SR dendrites. The magnitude of this effect was heterogeneous across different dendritic branches within the same neuron. These results predict that acetylcholine facilitates dendritic integration and NMDA spike generation in selected CA3 dendrites which could strengthen connections between specific CA3 neurons to form memory ensembles.
\end{abstract}

Keywords: Dendritic spikes, NMDA receptors, synaptic plasticity, hippocampus, CA3, computational modelling. 


\section{Introduction}

Episodic memories are encoded in the hippocampus by processing information from the entorhinal cortex within the dentate gyrus, CA3, CA2 and CA1 regions. Each region performs a distinct role for memory processing (Marr, 1971; McClelland and Goddard, 1996; Kesner and Rolls, 2015). CA3 is unique within the hippocampus because its excitatory pyramidal neurons are recurrently connected, allowing the emergence of CA3 networks with attractor dynamics (Marr, 1971; Hopfield, 1982; Kesner and Rolls, 2015; Guzman et al., 2016). Computationally, such networks are important for memory retrieval since they allow sparse external cues to drive attractor networks towards stable memory states; a process known as pattern completion (Gold and Kesner, 2005; Yassa and Stark, 2011). In order for the network to form new memory associations, it needs to adapt which neurons participate by selectively strengthening or weakening the recurrent excitatory synapses between CA3 pyramidal cells (Treves and Rolls, 1994; Tsodyks, 1999; Nakazawa et al., 2002; Rebola et al., 2017). In these cells, synaptic plasticity can be triggered by the coincident firing of action potentials (Debanne et al., 1998; Mishra et al., 2016), but recent evidence also suggests that dendritic spikes of $\mathrm{Ca}^{2+}$ caused by nonlinear synaptic integration and NMDA receptor (NMDAR) activation are highly effective at inducing synaptic plasticity (Golding et al., 2002; Brandalise et al., 2016; Mishra et al., 2016; Weber et al., 2016).

There are 3 major excitatory inputs to CA3 pyramidal neurons: mossy fiber inputs from dentate gyrus granule cells, perforant path inputs from entorhinal cortex layer II and recurrent associational/commissural inputs from CA3 pyramidal neurons (Witter, 2007; Hunt et al., 2018). Each of these inputs synapse onto different regions of the dendritic tree: mossy fibers onto the most proximal dendrites in the stratum lucidum (SL); perforant path onto the most distal dendrites in the stratum lacunosum-moleculare (SLM); and associational/commissural onto the mid region of the apical dendrites in the stratum radiatum (SR) as well as onto the basal dendrites in the stratum oriens (SO). Nonlinear synaptic summation and dendritic $\mathrm{Ca}^{2+}$ spikes can arise from near coincident activity at synapses either within or between these pathways (Makara and Magee, 2013; Brandalise and Gerber, 2014; Brandalise et al., 2016; Weber et al., 2016) but the precise configurations of synaptic activity required to drive dendritic spikes have not been fully explored.

Acetylcholine is released in response to salient, rewarding or arousing stimuli that require learning of new associations (Hasselmo, 2006; Teles-Grilo Ruivo and Mellor, 2013; LovettBarron et al., 2014; Hangya et al., 2015; Teles-Grilo Ruivo et al., 2017) and therefore is predicted to facilitate the formation of new memory ensembles in the hippocampus (Hasselmo et al., 1996; Hasselmo, 1999; Meeter et al., 2004; Prince et al., 2016). In line with this, 
acetylcholine facilitates NMDAR function and induction of synaptic plasticity (Markram and Segal, 1992; Marino et al., 1998; Buchanan et al., 2010; Fernández De Sevilla and Buño, 2010; Gu and Yakel, 2011; Dennis et al., 2016; Papouin et al., 2017). Disruption of cholinergic signalling impairs memory encoding (Berger-Sweeney et al., 2001; Anagnostaras et al., 2003; Rogers and Kesner, 2003). Importantly, activation of muscarinic M1 receptors on CA3 pyramidal neurons depolarizes the membrane potential and increases input resistance (Sun and Kapur, 2012). This is expected to increase cell excitability and is observed for regular spiking pyramidal neurons, but a sub-population of CA3 pyramidal cells respond specifically by reducing burst firing (Hunt et al., 2018). These effects result from inhibition of potassium channels including: M-type (Km) (Delmas and Brown, 2005), A-type (Ka) (Hoffman and Johnston, 1998), G-protein-coupled inwardly-rectifying (GIRK, Kir) (Sohn et al., 2007) and small-conductance $\mathrm{Ca}^{2+}$-activated channels (Kca (SK)) (Buchanan et al., 2010; Giessel and Sabatini, 2010). Integration of synaptic inputs and the nonlinear generation of dendritic spikes are highly sensitive to the intrinsic excitability of dendrites (Gulledge et al., 2005; Stuart and Spruston, 2015). Dendritic integration properties vary in different regions of the pyramidal neuron because of the shape of the dendritic tree and its non-uniform distribution of voltagegated ion channels (Spruston, 2008). Since neuromodulators such as acetylcholine regulate neuronal membrane conductances, they may also control dendritic spike generation and therefore synaptic plasticity and CA3 network ensemble formation (Prince et al., 2016; Fernández de Sevilla et al., 2020). Of the potassium channels that acetylcholine inhibits, Ka, Kca and Kir have been shown to modulate NMDAR-mediated dendritic spikes (NMDA spikes) (Cai et al., 2004; Makara and Magee, 2013; Malik and Johnston, 2017). Additionally, acetylcholine facilitates dendritic integration in neocortical layer $5 \mathrm{~b}$ pyramidal neurons (Williams and Fletcher, 2019) and in hippocampal OLM interneurons (Hagger-Vaughan and Storm, 2019).

Given the above findings, it is possible that acetylcholine enables CA3 network plasticity by two distinct mechanisms: first, by directly depolarising dendrites to increase local NMDAR activation and dendritic spine $\mathrm{Ca}^{2+}$ influx; or second, by boosting neural spiking and inducing Hebbian plasticity between recurrently connected neurons. In either case, it will be crucial to understand how acetylcholine affects dendritic integration and NMDA spikes in CA3 pyramidal neurons. We addressed this problem using computational models of 2-compartment and detailed reconstructed CA3 pyramidal neurons, exploring dendritic integration of both perforant path and SR recurrent associational/commissural inputs. We found that the degree of synaptic integration depended on distance from the soma and that simulated acetylcholine enhanced dendritic NMDA spikes by reducing the number of synapses required to cause nonlinear summation. 


\section{Methods}

All simulations were performed using NEURON software (Carnevale and Hines, 2006) and Python 3.8.

\begin{tabular}{l|c|c}
\multirow{2}{*}{ Channel } & \multicolumn{2}{|c}{ Peak conductance (S/cm ${ }^{2}$ ) } \\
\cline { 2 - 3 } & 2-compartment model & Reconstructed neuron model \\
\hline Ka & 0.398 & $5.56 \times 10^{-11}$ \\
Km & 0.033 & 0.0011 \\
Kca & 0.035 & 0.0012 \\
Kir & 0.0012 & $3.47 \times 10^{-6}$ \\
Leak (gpas) & $7.25 \times 10^{-5}$ & $4.4 \times 10^{-10}$ \\
Kdr & 0.005 & $4.6 \times 10^{-9}$ \\
Na & 0.0 & 0.0 \\
CaT, CaN, CaL & $1 \times 10^{-5}$ & $1 \times 10^{-5}$ \\
Kc & $5 \times 10^{-5}$ & $5 \times 10^{-5}$ \\
Kahp & 0.0001 & 0.0001 \\
Ih & 0.00001 & $5.6 \times 10^{-6}$
\end{tabular}

Table 1: Peak conductance parameters for all channels. Ka, Km, Kca, Kir and the leak peak conductances were optimised for both models as shown in Figure 1. Kdr and Ih peak conductances were additionally optimised in the reconstructed neuron model. The remaining conductance values were taken from Hemond et al., (2008).

\section{2-compartment model}

For the initial simulations, we used a 2-compartment model with a soma (500 $\mu \mathrm{m}^{2}$ area) and a dendrite $(1 \mu \mathrm{m}$ diameter $\times 200 \mu \mathrm{m}$ length). We set the axial resistivity to $150 \mathrm{M} \Omega$ and the leak reversal potential to $-65 \mathrm{mV}$. We took the channels included from a previous CA3 neuron model (Hemond et al., 2008) and included a sodium channel, several potassium channels (Atype, M-type, delayed-rectifier), $\mathrm{Ca}^{2+}$ channels (L-type, N-type, T-type), Ca ${ }^{2+}$-activated potassium channels $\left(K_{A H P}, B K\right)$ and a hyperpolarization-activated current $\left(I_{h}\right)$. For these simulations, we set the sodium channel conductance to zero to prevent action potentials. In order to capture the effects of acetylcholine, we added two extra conductances to this model: a small-conductance $\mathrm{Ca}^{2+}$-activated potassium channel (Kca or SK channel; (Combe et al., 2018)) and an inwardly-rectifying potassium channel (Kir or GIRK channel; (Martinello et al., 2019). To build the model with reasonable contributions of the relevant potassium channels, 
bioRxiv preprint doi: https//doi.org/10.1101/2021.03.01.433406; this version posted March 2, 2021. The copyright holder for this preprint (which was not certified by peer review) is the author/funder, who has granted bioRxiv a license to display the preprint in perpetuity. It is made available under aCC-BY-NC 4.0 International license.

the conductance of each channel was optimised to best fit with experimental data (Figure 1). This was done by implementing a covariance matrix adaptation evolution strategy (Hansen, 2016; Jȩdrzejewski-Szmek et al., 2018) in which parameters were adjusted in order to match outputs from the model as closely as possible with experimental measurements of resting membrane potential and input resistance. The optimisation was implemented using the PyCMA package (https://github.com/CMA-ES/pycma). Here, we optimised the Ka, Km, Kca, $\mathrm{Kir}$ and leak peak conductances, as well as shifts in the voltage-activation curves for $\mathrm{Ka}, \mathrm{Km}$ and Kir channels, using published data describing the changes in membrane potential and input resistance upon blocking each of the channels experimentally (Figure 1, (Sun and Kapur, 2012; Makara and Magee, 2013)). The experimental data was obtained from two different studies, with the Ka, Kca and Kir data from one study (Makara and Magee, 2013) and the Km and acetylcholine receptor data from a separate study (Sun and Kapur, 2012). To account for this, the target membrane potential and input resistance values for $\mathrm{Km}$ and acetylcholine were adjusted slightly to reflect the different resting membrane potentials of the two experimental set ups. Peak conductances for all channels are displayed in Table 1. NMDAR-containing synapses (NMDA synapses) were modelled with a dual exponential model that included a voltage-dependent magnesium block as in Baker et al., (2011). The NMDA synapse had a rise time of $4 \mathrm{~ms}$ and a decay time of $42 \mathrm{~ms}$.

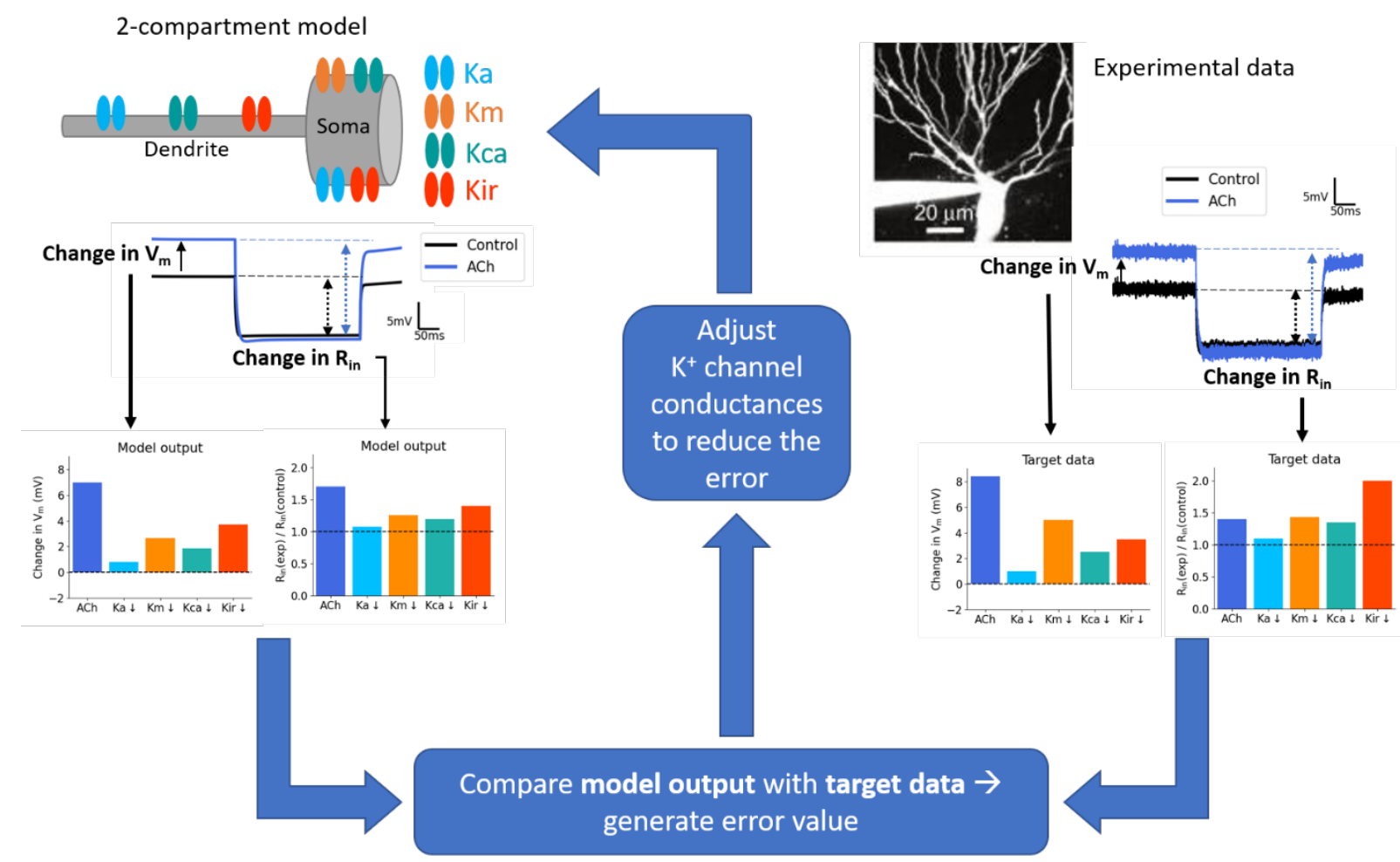

Figure 1: Optimisation of potassium conductances in 2-compartment model. Potassium channel conductance parameters were optimised by fitting to experimental data (from Makara and Magee (2013) and Sun and Kapur (2012)) measuring the change in membrane potential and input resistance after inhibiting the relevant potassium conductance. The error represented the difference between the model output and the target data which 
then fed back into the optimisation algorithm to adjust the potassium conductances. This cycle was repeated many times until the error was minimised. The bar plots shown represent the target experimental data used (right) and the final optimised output in the model (left). Neuron image adapted from Makara and Magee (2013). $V_{m}=$ resting membrane potential; $\mathrm{R}_{\mathrm{in}}=$ input resistance; $\mathrm{Ka}=\mathrm{A}$-type potassium channel, $\mathrm{Km}=\mathrm{M}$-type potassium channel, $\mathrm{Kca}$ = SK channel, Kir = GIRK channel.

\section{Reconstructed CA3 pyramidal neuron model}

This model was based on the 943-compartment model from Hemond et al. (2008), reconstructed from a filled rat CA3 pyramidal neuron. It contained the same conductances as the 2-compartment model but the distribution of the Ka and Kir conductance varied along the dendritic arbour, as reported experimentally (Kim et al., 2012; Degro et al., 2015). The optimisation process of the potassium conductances (Figure 1) was repeated separately for this model (Table 1). To adjust for the lack of dendritic spines in the model, the membrane capacitance and resistance were doubled and halved, respectively, in all dendritic compartments. The dendritic regions were divided based on their distance from the soma (SL dendrites < 150 $\mu \mathrm{m}$; SR dendrites 150-400 $\mu \mathrm{m}$; SLM dendrites $>400 \mu \mathrm{m}$, Figure 3A). AMPARcontaining synapses (AMPA synapses), with a rise and decay time of 0.5 and $1.5 \mathrm{~ms}$, respectively, and $0.5 x$ the peak conductance of NMDA synapses, were also included in this model (Table 2). Synapses were positioned $1 \mu \mathrm{m}$ apart and stimulated synchronously. The AMPA and NMDA synapse models and parameters were taken from a previous model (Baker et al., 2011; Hyun et al., 2015), fit to experimental results. However, to generate nonlinearity in single dendrite branches the NMDA:AMPA ratio was increased from 0.2 to 2 . This higher ratio is common in other models that have investigated NMDA spikes (Poirazi et al., 2003;

\begin{tabular}{r|c|c} 
& \multicolumn{2}{|c}{ Model parameters } \\
\cline { 2 - 3 } & $\begin{array}{c}\text { 2-compartment } \\
\text { model }\end{array}$ & $\begin{array}{c}\text { Reconstructed } \\
\text { neuron model }\end{array}$ \\
\hline Axial resistivity $(\Omega \mathrm{cm})$ & 150 & 150 \\
Membrane capacitance $($ soma $)\left(\mu \mathrm{f} / \mathrm{cm}^{2}\right)$ & 0.7 & 0.7 \\
Membrane capacitance (dendrites) $\left(\mu \mathrm{f} / \mathrm{cm}^{2}\right)$ & 1.4 & 1.4 \\
Membrane resistance $($ soma $)\left(\mathrm{k} \Omega \mathrm{cm}^{2}\right)$ & 14 & $2 \times 10^{6}$ \\
Membrane resistance (dendrites) $\left(\mathrm{k} \Omega \mathrm{cm}^{2}\right)$ & 7 & $1 \times 10^{6}$ \\
\cline { 2 - 3 } NMDA rise time constant $(\mathrm{ms})$ & 4 & 5 \\
\cline { 2 - 3 } NMDA decay time constant $(\mathrm{ms})$ & 42 & 16 \\
AMPA rise time constant $(\mathrm{ms})$ & - & 0.5 \\
AMPA decay time constant $(\mathrm{ms})$ & - & 1.5 \\
NMDA peak conductance $(\mathrm{nS})$ & 1 & 0.585 \\
AMPA peak conductance $(\mathrm{nS})$ & - &
\end{tabular}

Table 2: Model and synapse parameters. 
Larkum et al., 2009; Major et al., 2013). All simulations were run with a timestep of $1 \mathrm{~ms}$.

\section{NMDA spike generation and analysis}

NMDA spikes were generated by increasing either the synaptic weight of the NMDAR conductance (2-compartment model) or the number of synapses (reconstructed neuron model), from 1 to 20 , causing a nonlinear increase in the amplitude of the voltage response. In simulations with AMPA synapses included, we also ran the model with only AMPA synapses (and no NMDA) and subtracted these voltage traces from the original to determine peak the amplitude of the NMDA voltage response. To assess the effect of blocking the potassium channels on the nonlinearity curve, we calculated and compared the maximum slope of the curve and the synaptic weight or number of synapses at the maximum slope.

\section{Inhibition of potassium channels and simulating acetylcholine}

The potassium conductances were blocked in the model by setting their conductance to zero. To simulate acetylcholine, the extent of inhibition for each potassium channel was determined during parameter optimisation. This resulted in a $50 \%$ block of the A-type potassium (Ka), Mtype potassium $(\mathrm{Km})$, and SK (Kca) conductances and an $80 \%$ block of the GIRK (Kir) conductance to simulate acetylcholine. 
bioRxiv preprint doi: https://doi.org/10.1101/2021.03.01.433406; this version posted March 2, 2021. The copyright holder for this preprint (which was not certified by peer review) is the author/funder, who has granted bioRxiv a license to display the preprint in perpetuity. It is made available under aCC-BY-NC 4.0 International license.

\section{Results}
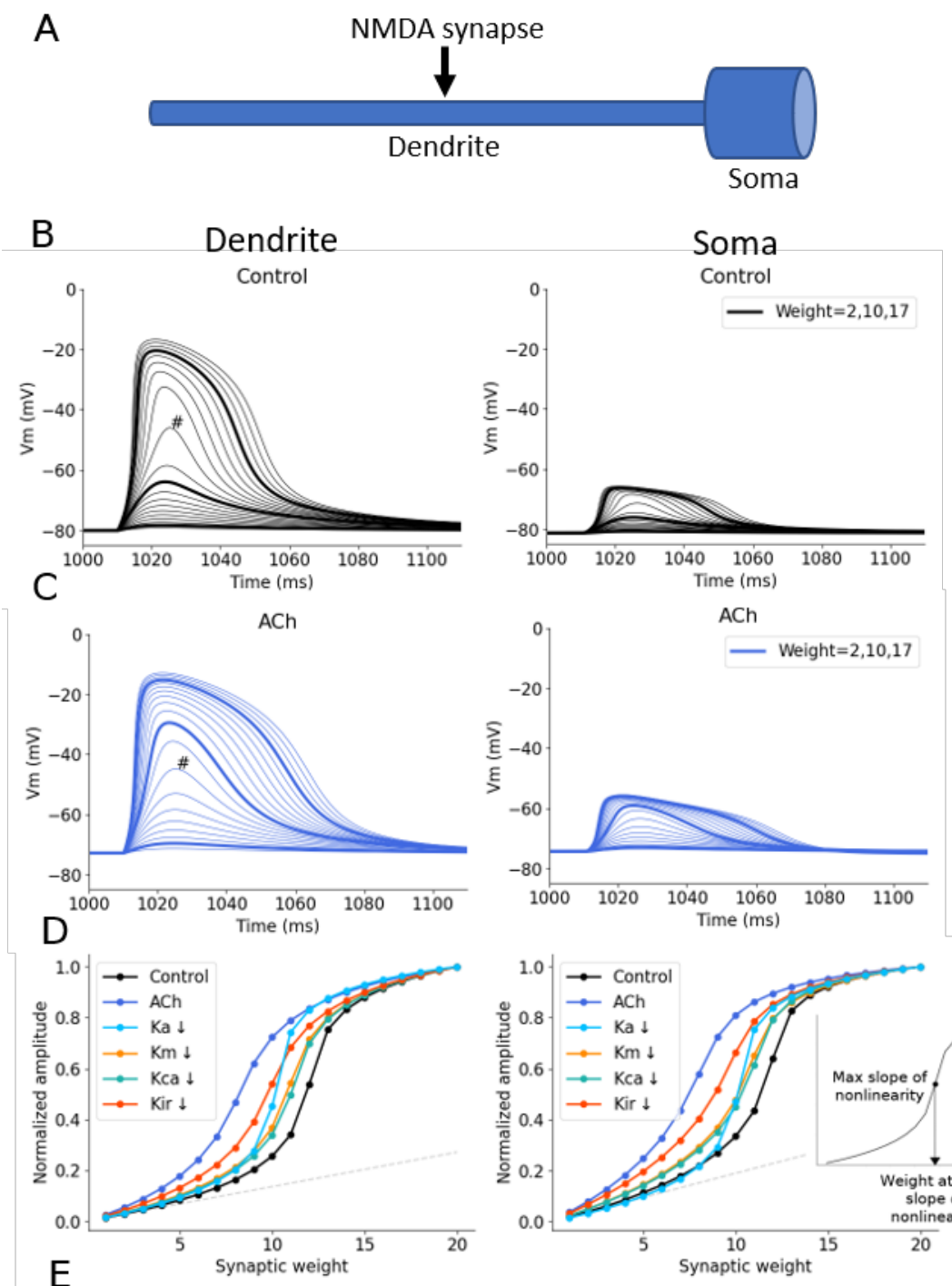

$\mathrm{E}$
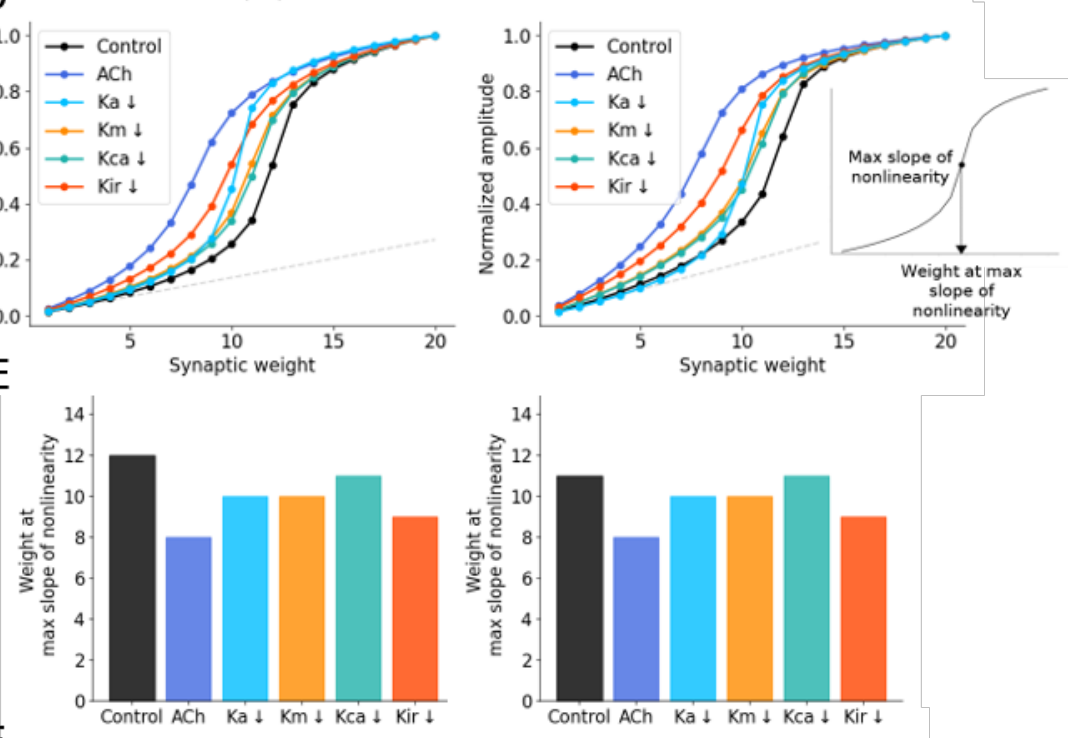

$\mathrm{F}$

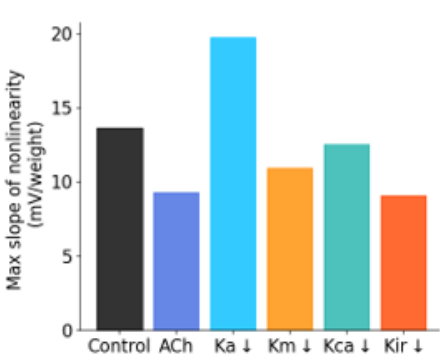

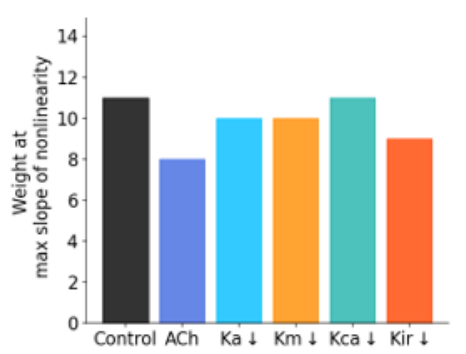

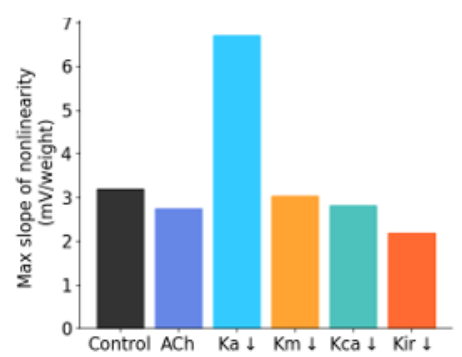

Figure 2: Simulated acetylcholine reduces the synaptic weight at the maximum slope of nonlinearity. (A) Schematic of 2-compartment model. (B) Example voltage traces with increasing synaptic weight measured in the dendritic compartment (left) and somatic compartment (right). $\#$ = the weight at the maximum slope of nonlinearity. (C) Example voltage traces with simulated acetylcholine. (D) Effect of inhibiting potassium conductances on the supralinear increase in voltage response amplitudes with increasing synaptic weight recorded at the dendrite (left) and soma (right). Inset shows how the maximum slope and respective synaptic weight, described in the bar plots in $E$ and $F$ below, are calculated. (E) Change in the synaptic weight at the maximum slope of nonlinearity for each condition. $(F)$ Change in the maximum slope of nonlinearity for each condition.

\section{Acetylcholine}

\section{increases nonlinear}

synaptic integration

\section{in a 2-compartment}

neuron model.

We initially used a 2compartment model of a soma and dendrite to investigate how acetylcholine may affect NMDARmediated nonlinear

synaptic integration (Figure 2A). An NMDA-only synapse with peak conductance $1 \mathrm{nS}$ was located on the dendritic compartment and the synaptic weight increased from 1- to 20-fold while recording the resulting voltage in the somatic and dendritic compartments (Figure 2B). 
Increasing synaptic weight caused a nonlinear increase of postsynaptic response (Figure 2D) as expected for voltage-dependent NMDA synapses. We simulated acetylcholine by reducing the potassium conductances $\mathrm{Ka}, \mathrm{Km}$, $\mathrm{Kca}$ by $50 \%$ and $\mathrm{Kir}$ by $80 \%$, as determined by parameter optimisation (see Methods). Reduction of these channel conductances in the model increased the resting membrane potential by $\sim 7 \mathrm{mV}$ and the input resistance by $\sim 70 \%$ (Figure 2C, D), comparable to experimental data (Figure 1) (Sun and Kapur, 2012). Reducing the potassium conductances increased neuron excitability and enhanced the NMDA response so that less synaptic input was needed to achieve similar amplitude voltage responses in both dendritic and somatic compartments (Figure 2C, D) and shifting the maximum slope of nonlinearity (Figure 2D) from a synaptic weight of 12 to 8 (Figure 2E+F).

To determine individual potassium channel contributions to the increase in nonlinearity seen with acetylcholine, we reduced each potassium channel conductance separately, by $100 \%$. Inhibiting Ka, Km or Kca conductances separately produced a small reduction in the synaptic weight needed to reach nonlinearity, with Kir inhibition causing a slightly larger reduction indicating that no single potassium channel underpinned the effect of acetylcholine (Figure 2D, E). Conversely, inhibition of the A-type potassium conductance caused a considerable increase in the slope of nonlinearity (Figure 2D, F), not observed when blocking any other potassium channel, or when simulating acetylcholine.

\section{Heterogeneity of nonlinear synaptic integration across dendrites in a reconstructed}

\section{CA3 neuron model}

We next tested the findings from the 2-compartment model in a reconstructed CA3 neuron model. We simulated 1-20 identical synapses, with both AMPA and NMDA components, on individual dendritic branch sections, $1 \mu \mathrm{m}$ apart, in the SR or SLM region in a reconstructed CA3 pyramidal neuron model (Figure 3A) (see Methods). The synapses on SR dendrites represent recurrent inputs from neighbouring CA3 pyramidal neurons whereas the synapses on SLM dendrites represent inputs from layer II of the entorhinal cortex. The synaptic voltage responses had both a fast AMPAR-based component and a slower NMDAR based component (Figure $3 \mathrm{~B}$ ). To isolate the NMDA component of the voltage response, we calculated the difference in the voltage traces between simulations containing both AMPAR and NMDAR synapses, and simulations containing AMPAR-only synapses. Increasing numbers of synapses on any dendritic branch resulted in monotonically larger voltage responses, increased nonlinear integration, and NMDA spikes (represented by the slower NMDA component of the synaptic response). Notably the threshold for initiation of NMDA spikes varied substantially between dendrites. Overall, the amplitude of the dendritic NMDA response increased with distance of the dendrite section from the soma, whereas the opposite was true 
bioRxiv preprint doi: https://doi.org/10.1101/2021.03 01.433406; this version posted March 2, 2021. The copyright holder for this preprint (which was not certified by peer review) is the author/funder, who has granted bioRxiv a license to display the preprint in perpetuity. It is made available under aCC-BY-NC 4.0 International license.

for somatic responses, which decreased with dendrite distance from the soma (Figure 3B-E). This was reflected in a shift in the number of synapses required to initiate nonlinear NMDA responses, with fewer synapses generally required to produce nonlinearity in the more distal dendrites.

B

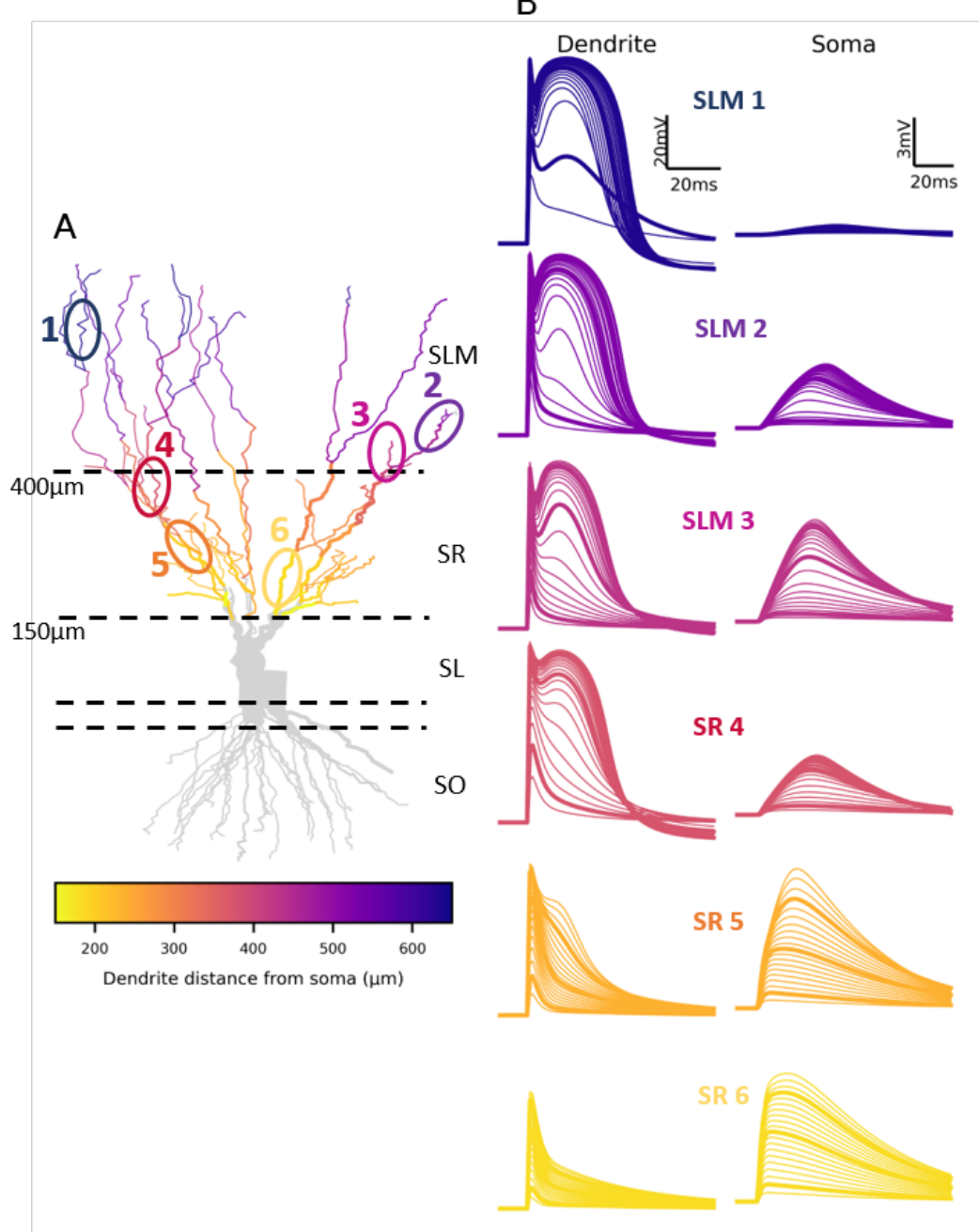

C
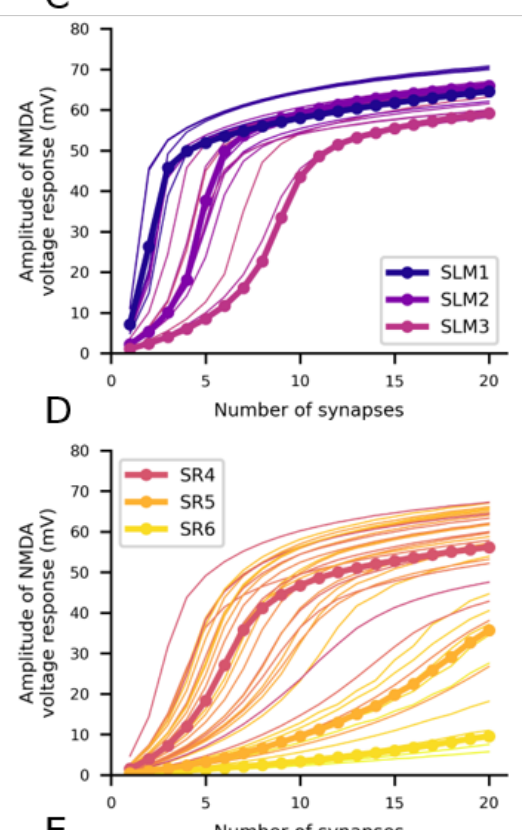

$\mathrm{E}$

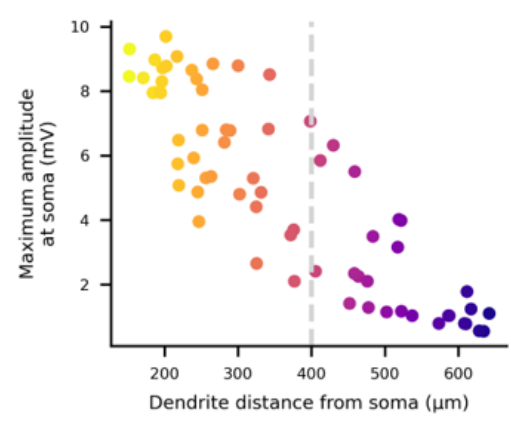

Figure 3: Nonlinearity of synaptic integration varies for dendrites across the proximal-distal axis. (A) Morphology of the reconstructed CA3 neuron model. Dashed lines separate the different strata as labelled on the right with their distance from the soma on the left. Coloured dendrites are the ones included in the generation of the plots in C-E. The circled and numbered sections represent the voltage plot examples in B. (B) Example voltage traces generated by increasing synapse numbers in different dendrite sections recorded in the stimulated dendrite (left) and at the soma (right). Note the different scales for the soma and dendrite recordings. (C) Nonlinearity plots from all the coloured SLM dendrites in A. (D) Nonlinearity plots from all the coloured SR dendrites in A. (E) Maximum voltage response amplitude recorded at the soma decreases with stimulated dendrite distance from the soma.

Subsequently, we investigated the cause of the dendritic variation in nonlinear synaptic integration by regressing the nonlinearity slope and offset against dendritic distance from soma and dendrite local input resistance (Figure 4). The results shown in Figure 3 indicated that increasing dendritic distance from the soma was correlated with fewer synapses at the 
maximum slope of nonlinearity and we found that this was the case (Figures $4 A, B, S R R^{2}=$ 0.364 ; SLM R ${ }^{2}=0.496$ ). A possible mechanism for this proximal-distal correlation is increased input resistance in distal dendrites, which would enhance voltage responses to synaptic input and engage nonlinear NMDA conductances. Indeed, the input resistance was well correlated with the number of synapses required for nonlinearity (Figure $4 C, S R R^{2}=0.826$; SLM $R^{2}=$ 0.793), showing a tighter relationship than that with dendritic distance. These observed effects were similar for the somatic recordings (Figures 4B, C, right). We also studied the dependence of maximum slope of nonlinearity on distance from the soma (Figures 4D-F). The slope of dendritic nonlinearity increased with distance from the soma $\left(S R R^{2}=0.250 ; S L M R^{2}=0.403\right.$ ) whereas the slope of somatic nonlinearity decreased with distance from the soma, primarily when stimulating the SLM dendrites (Figure 4E, SR $R^{2}=0.018$; $S L M R^{2}=0.433$ ) and possibly due to attenuation of the response. Dendritic input resistance was also correlated with the slope of nonlinearity (Figure $4 F, S R R^{2}=0.883$; $S L M R^{2}=0.587$ ). To summarise, dendritic distance from the soma and input resistance can explain the differences in the generation of NMDA nonlinearity between dendrites. 

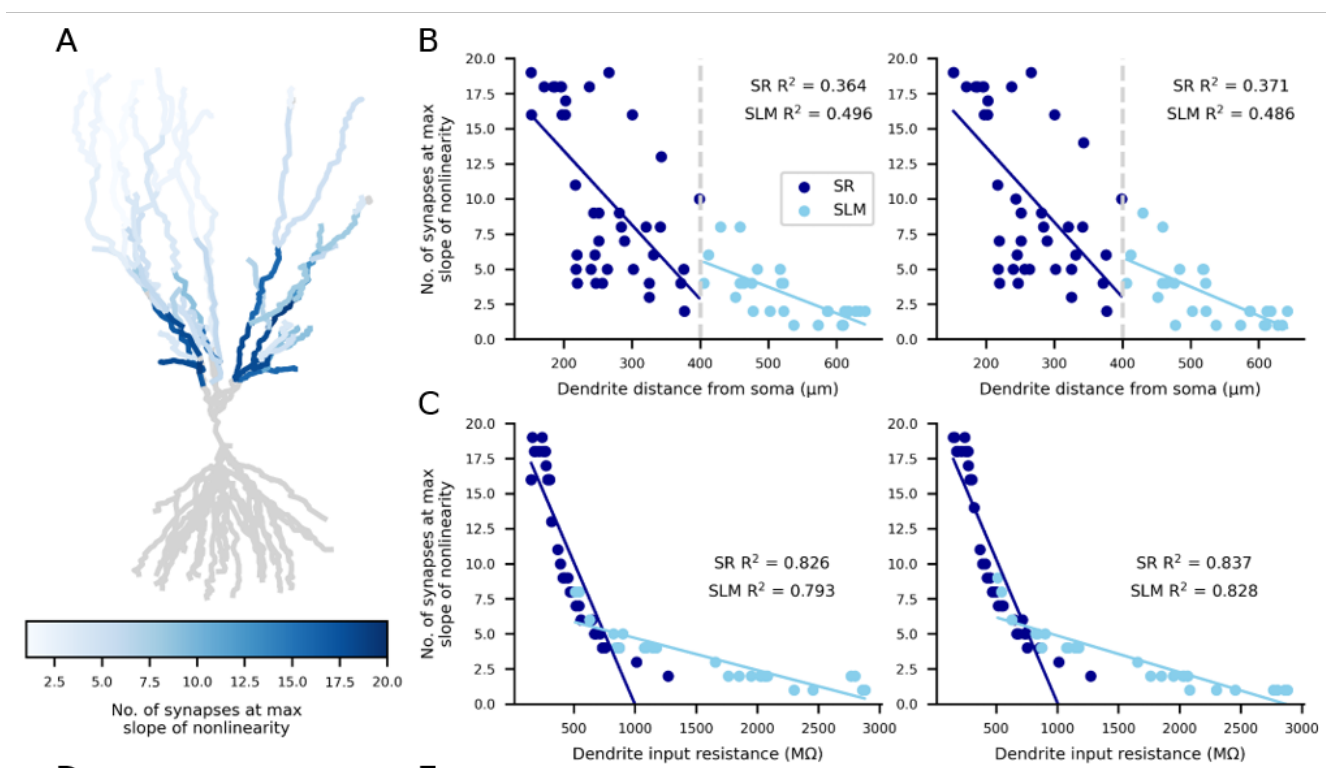

D

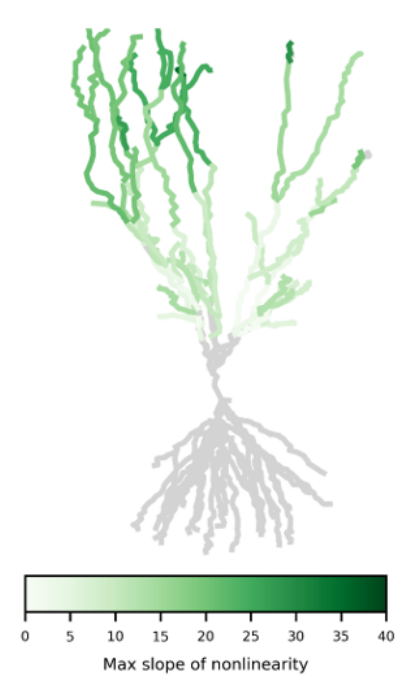

$\mathrm{E}$
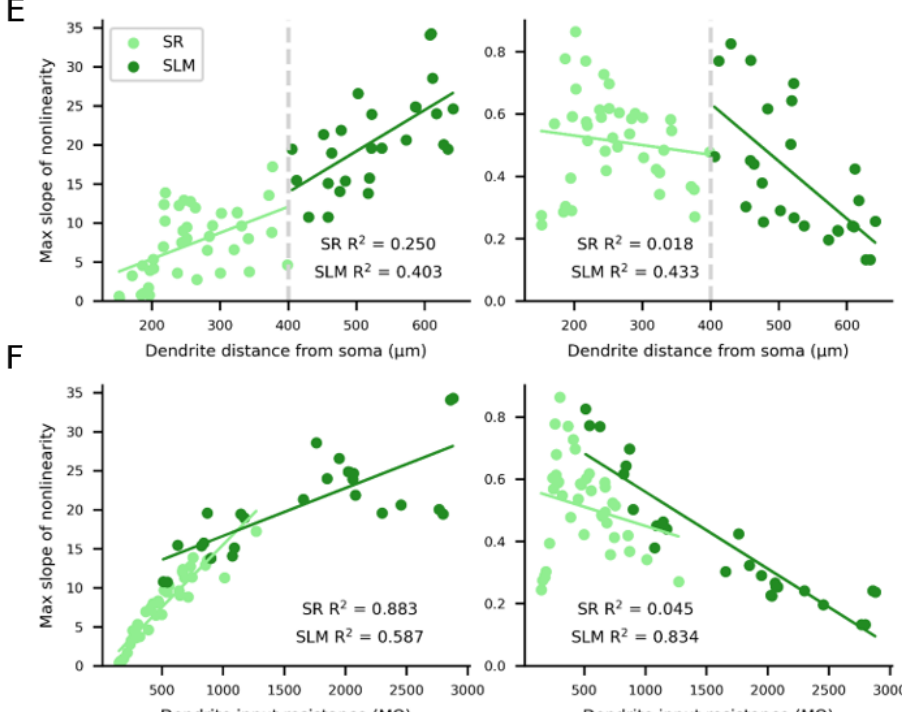

Dendrite distance from soma $(\mu \mathrm{m})$

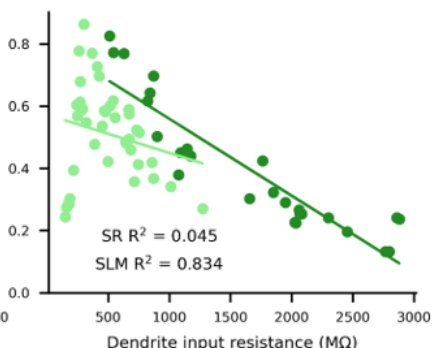

Figure 4: The number of synapses at the maximum slope of nonlinearity reduces with distance from the soma due to increased dendritic input resistance. ( $A+B)$ Number of synapses at the maximum slope of nonlinearity decreases with dendrite distance from the soma. Colour coding for entire neuron shown in $A$ with individual dendrites quantified in B. (C) An increasing dendritic input resistance reduces the number of synapses at the maximum slope of nonlinearity. $(D+E)$ The maximum slope of nonlinearity increases with distance from the soma as recorded in the dendrite, however when recorded at the soma (E, right), the maximum slope decreases in the SLM dendrites with distance from the soma. Colour coding for entire neuron shown in $D$ with individual dendrites quantified in $E$. (F) An increasing dendritic input resistance increases the maximum slope of nonlinearity in the dendrite (left) but reduces the maximum slope in the soma (right).

\section{Acetylcholine boosts nonlinear synaptic integration in the reconstructed neuron} model.

Next, we investigated the impact of acetylcholine on nonlinear synaptic integration in the reconstructed neuron (Figure 5). We simulated acetylcholine as described in the 2compartment model. Similar to the 2-compartment model, acetylcholine depolarised the neuron's resting potential and enhanced voltage responses to synaptic stimulation (Figure 
bioRxiv preprint doi: $h t t p s: / / d o i . o r g / 10.1101 / 2021.03 .01 .433406$; this version posted March 2, 2021. The copyright holder for this preprint (which was not certified by peer review) is the author/funder, who has granted bioRxiv a license to display the preprint in perpetuity. It is made available under aCC-BY-NC 4.0 International license.

$5 \mathrm{~B})$. This was reflected in a reduction in the number of synapses required to generate nonlinear synaptic integration in each of the example dendrites (Figure $5 \mathrm{C}$ ). The magnitude of the effect varied across dendrites but was true for the majority of both SR and SLM dendrites, with up to 5 fewer synapses needed for nonlinearity in the SR dendrites, and up to 2 fewer synapses in the SLM dendrites (Figure 5D). Furthermore, acetylcholine reduced the slope of nonlinearity in most dendrites, similar to the 2-compartment model (Figure 5E).

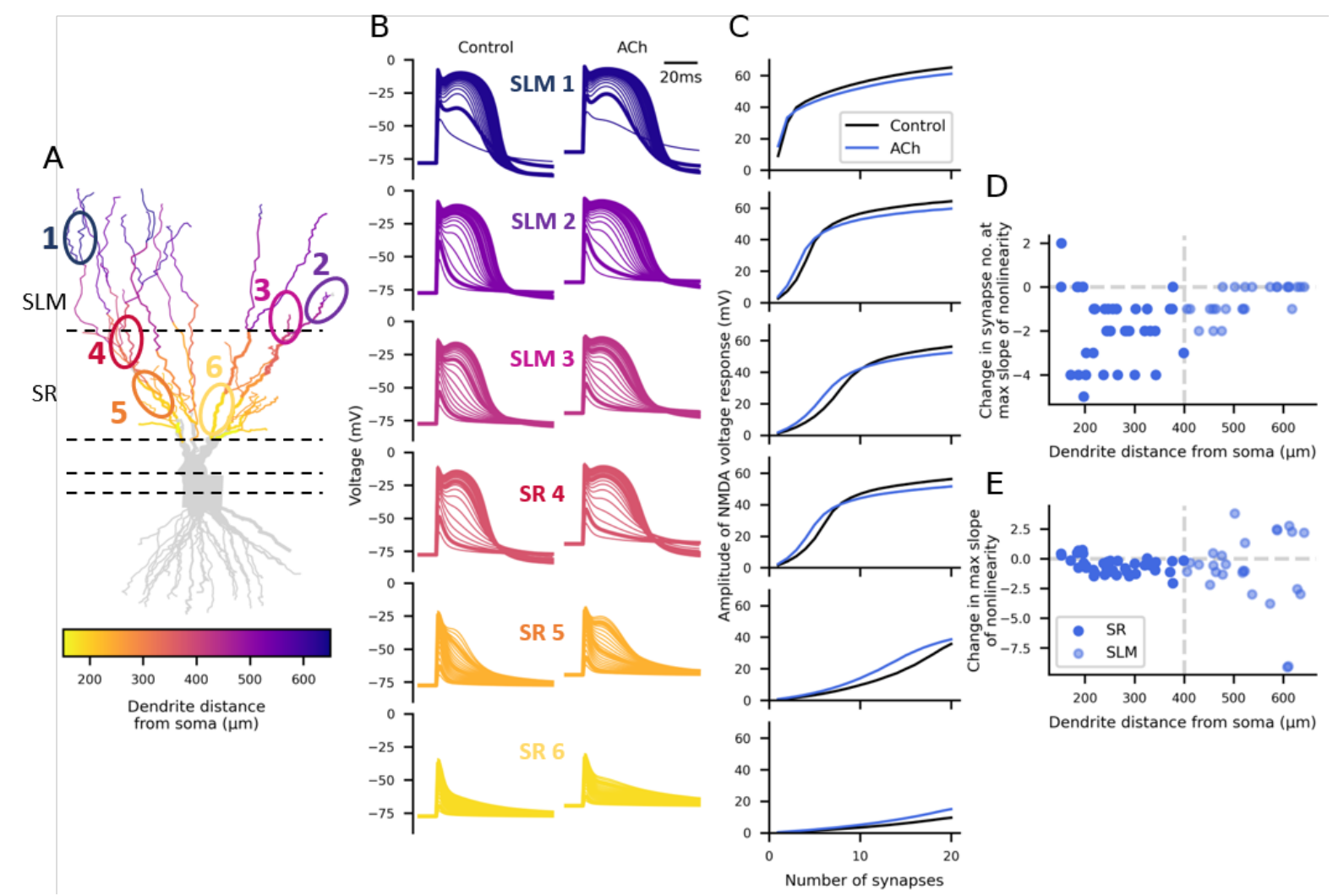

Figure 5: Acetylcholine boosts nonlinear synaptic integration in most dendrites. (A) Morphology of the reconstructed CA3 neuron model. Coloured dendrites are the ones included in the generation of the plots in $D$ and $E$. The circled and numbered sections represent the voltage plot examples and nonlinear curves in B and $C$. (B) Example dendritic voltage traces of increasing synapse numbers in different dendrite sections recorded in the stimulated dendrite (left) and then with simulated acetylcholine (right). (C) Nonlinearity curves for control (black) and acetylcholine (blue) for each example dendrite in B. (D) The change in number of synapses at the maximum slope of nonlinearity with acetylcholine for all SR and SLM dendrites. (E) The change in the maximum slope of nonlinearity with acetylcholine for all the SR and SLM dendrites. 
bioRxiv preprint doi: https://doi.org/10.1101/2021.03.01.433406; this version posted March 2, 2021. The copyright holder for this preprint (which was not certified by peer review) is the author/funder, who has granted bioRxiv a license to display the preprint in perpetuity. It is made available under aCC-BY-NC 4.0 International license.
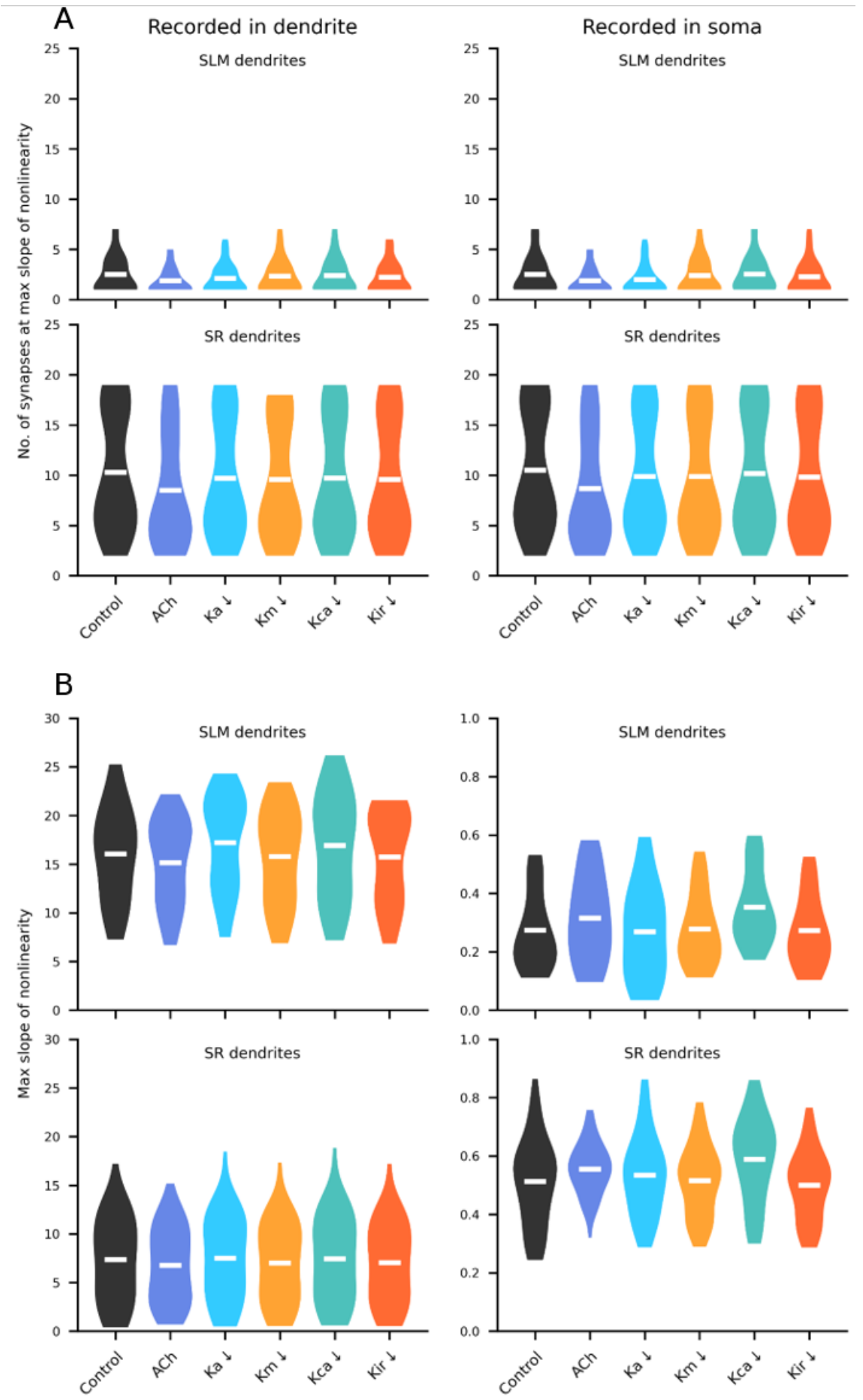

Figure 6: Acetylcholine reduces the number of synapses at the maximum slope of nonlinearity in the reconstructed neuron model. Violin plots of density of measurements across all dendrites, white bars represent the mean. (A) Acetylcholine reduces the number of synapses at the maximum slope of nonlinearity in SLM (top) and SR (bottom) dendrites. (B) Change in the maximum slope of nonlinearity for each condition in the SLM (top) and SR
We then calculated the average effect of acetylcholine across all SR and SLM dendrites, as well as the inhibition of individual potassium channel conductances (Figure 6). On average, acetylcholine reduced the number of synapses required to initiate nonlinearity from $2.50 \pm$ 0.37 to $1.88 \pm 0.25$ in the SLM dendrites and from $10.30 \pm 0.92$ to $8.50 \pm 0.88$ in the $S R$ dendrites (mean \pm standard error; Figure 6A). This effect was similar in the somatic response (SLM: from $2.50 \pm 0.38$ to $1.88 \pm$ 0.25 ; SR: from $10.53 \pm$ 0.92 to $8.70 \pm 0.88$ ). Again, no one particular potassium conductance could fully account for the effect of acetylcholine. In the 2compartment model, blocking the Ka channel increased the slope of nonlinearity. We also found this effect in the reconstructed neuron model, to a much lesser extent, and only in the SLM dendrites (Figure 6B). This is likely because Ka channel density increases with distance from the soma in the model in line with experimental data (Kim et al., 2012). Therefore, inhibition of Ka conductances in the distal SLM dendrites causes a greater effect. Blocking the 
Kca channel also seemed to slightly increase the slope of nonlinearity, but at the soma, as opposed to in the dendrites. To summarise, the results in the reconstructed neuron model reflect the conclusions from the 2-compartment model, in which acetylcholine reduces the number of synapses required for nonlinearity and blocking the Ka conductance increases the slope of nonlinearity.

\section{Discussion}

In a reconstructed CA3 neuron model, we have shown that simulating acetylcholine reduced the number of synapses required for nonlinear integration of glutamatergic synaptic inputs in SR and SLM dendrites. We have also demonstrated that dendrite distance from the soma and input resistance correlate with the dendrite's ability to generate nonlinearity, with distal dendrites with a higher input resistance more readily producing nonlinearity. Additionally, the A-type potassium channel $(\mathrm{Ka})$ modulated the slope of nonlinearity in the distal SLM dendrites, where there is a higher proportion of Ka channels.

Nonlinear synaptic integration has previously been studied in CA3 pyramidal neurons ex vivo. Makara and Magee (2013) observed NMDAR-mediated nonlinearity in SR and SO CA3 dendrites with glutamate uncaging. In terms of variability between dendrite branches, they characterized two populations with a fast or slow NMDA spike decay time. They did not report a correlation between dendrite distance from the soma and NMDA spike decay time but determined the GIRK channel as primarily responsible for regulating the decay time. Here, we did not analyse the NMDA spike decay time but there did not seem to be a major effect from blocking the potassium channels individually on the onset of nonlinearity. However, of all the channels, blocking the Kir channel displayed the greatest impact on the nonlinearity threshold and therefore could play an important role in the modulation of NMDA spikes. Kim et al., (2012) analysed dendritic sodium spikes in CA3 neurons and reported a reduced threshold with increasing distance from the soma, in accordance with the NMDA spike threshold results displayed here. Differences in dendrite ability to generate sodium spikes has also been noted in CA1 oblique dendrites (Losonczy et al., 2008) where distinct strong or weak branch populations were identified. However, in contrast with the data from CA3 neurons, the branches closer to the soma were more readily able to generate dendritic sodium spikes. This variation in dendrite ability to generate dendritic spikes suggests that certain synaptic inputs can be prioritised. 
The effect of acetylcholine on dendritic integration has been previously investigated in the somatosensory cortex (Williams and Fletcher, 2019). Optogenetically released acetylcholine increased apical dendrite excitability, facilitated the integration of inputs, and caused long duration dendritic plateau potentials that impacted action potential burst firing. This cholinergic modulation of dendritic integration was mediated by the facilitation of R-type $\mathrm{Ca}^{2+}$ channels. The cholinergic enhancement of dendritic excitability and integration supports the results shown here. Furthermore, in CA1 neurons (Losonczy et al., 2008), $5 \mu \mathrm{M}$ carbachol, combined with repetitive spike generation in weak branches, selectively enhanced the weak branch sodium spike strength and its propagation into stronger proximal branches. This is in line with the data shown here in which acetylcholine affects the SR dendrites, with a higher NMDA spike threshold, more so than the SLM dendrites that are already capable of generating nonlinearity with minimal synaptic input. This suggests that acetylcholine selectively facilitates NMDA spike generation in the SR dendrites and could therefore impact CA3-CA3 recurrent synaptic plasticity by increasing $\mathrm{Ca}^{2+}$ influx to synapses from both local voltage-gated $\mathrm{Ca}^{2+}$ channels and from the NMDARs themselves. Acetylcholine also alters somatic excitability of CA3 pyramidal neurons but the nature of the modulation depends on the type of pyramidal neuron. Athorny, burst firing neurons reduce their burst firing in response to acetylcholine whereas thorny regular firing neurons increase their firing rate (Hunt et al., 2018). This may reflect varying balances of ion channel conductances at the soma and it is not clear if these are also found in the dendrites.

We also found that the A-type potassium channel regulated the slope of nonlinearity. This measure does not relate to the absolute number of synapses needed to reach the nonlinearity, but rather the steepness of the response amplitude as further synapses are activated. This result reflects a previous study in which blocking the A-type potassium channel increased the dendritic plateau potential amplitude in CA1 apical dendrites (Cai et al., 2004). Downregulation of this channel also increased the weak branch sodium spike strength in CA1 dendrites (Losonczy et al., 2008), highlighting its importance in CA1 nonlinear integration.

\section{Functional implications}

This study predicts that acetylcholine facilitates NMDA spike generation in CA3 dendrites. NMDA spikes have been shown to be necessary for generating timing-dependent associative plasticity at CA3-CA3 recurrent synapses (Brandalise et al., 2016). Therefore, the presence of acetylcholine could facilitate this plasticity, by lowering the threshold for NMDA spike initiation, and strengthen these connections to enable new memory ensembles to form. Alternatively, promotion of spiking in CA3 neurons by NMDA spikes (Makara and Magee, 
2013) could induce spike timing-dependent plasticity at CA3-CA3 recurrent synapses (Mishra et al., 2016).

NMDAR-dependent dendritic plateau potentials that mediate nonlinear integration have been shown to induce plasticity that underlies CA1 place field firing (Bittner et al., 2015, 2017). Neuromodulatory input form the locus coeruleus has been shown to be important for promoting CA1 place cell formation around new reward locations (Kaufman et al., 2020), as well as enhancing CA1 dendritic excitability and LTP (Liu et al., 2017; Bacon et al., 2020). Taking into consideration these studies and the results shown here, acetylcholine could also be implicated in place cell generation by facilitating dendritic excitability and NMDAR-mediated plateau potentials (Prince et al., 2016; Fernández de Sevilla et al., 2020).

Interestingly, acetylcholine had a heterogeneous effect on excitability of different dendrites. In some dendrites it lowered the NMDA spike threshold by $\sim 50 \%$, while in others it caused no reduction in threshold. This heterogeneity implies that acetylcholine release could shift the relative sensitivities of somatic voltage to synaptic inputs on different dendrites, as opposed to just implementing a uniform increase in sensitivity to all inputs. Future studies on the effects of acetylcholine in neural circuits could address how this effect would modulate information flow and ensemble formation in CA3 networks.

In conclusion, this study predicts that acetylcholine facilitates the generation of NMDA spikes in CA3 pyramidal neuron dendrites, which could provide an important mechanism for the storage of new memories in hippocampal circuitry.

\section{Acknowledgements}

We thank Simonas Griesius and Rahul Gupta for helpful discussions. This work was supported by Wellcome Trust (RH PhD studentship, JRM 101029/Z/13/Z), BBSRC (JRM, BB/R002177/1), MRC (COD, MR/S026630/1), and Leverhulme Trust (COD, RPG-2019-229).

Declarations of interest: none

\section{References}

Anagnostaras SG, Murphy GG, Hamilton SE, Mitchell SL, Rahnama NP, Nathanson NM, Silva AJ (2003) Selective cognitive dysfunction in acetylcholine M1 muscarinic receptor mutant mice. Nat Neurosci 6:51-58.

Bacon TJ, Pickering AE, Mellor JR (2020) Noradrenaline release from locus coeruleus 
terminals in the hippocampus enhances excitation-spike coupling in ca1 pyramidal neurons via $\beta$-adrenoceptors. Cereb Cortex 30:6135-6151.

Baker JL, Perez-Rosello T, Migliore M, Barrionuevo G, Ascoli GA (2011) A computer model of unitary responses from associational/commissural and perforant path synapses in hippocampal CA3 pyramidal cells. J Comput Neurosci 31:137-158.

Berger-Sweeney J, Stearns NA, Murg SL, Floerke-Nashner LR, Lappi DA, Baxter MG (2001)

Selective immunolesions of cholinergic neurons in mice: Effects on neuroanatomy, neurochemistry, and behavior. J Neurosci 21:8164-8173.

Bittner KC, Grienberger C, Vaidya SP, Milstein AD, Macklin JJ, Suh J, Tonegawa S, Magee JC (2015) Conjunctive input processing drives feature selectivity in hippocampal CA1 neurons. Nat Neurosci 18:1133-1142.

Bittner KC, Milstein AD, Grienberger C, Romani S, Magee JC (2017) Behavioral time scale synaptic plasticity underlies CA1 place fields. Science 357:1033-1036.

Brandalise F, Carta S, Helmchen F, Lisman J, Gerber U (2016) Dendritic NMDA spikes are necessary for timing-dependent associative LTP in CA3 pyramidal cells. Nat Commun $7: 13480$.

Brandalise F, Gerber U (2014) Mossy fiber-evoked subthreshold responses induce timingdependent plasticity at hippocampal CA3 recurrent synapses. Proc Natl Acad Sci 111:4303-4308.

Buchanan KA, Petrovic MM, Chamberlain SEL, Marrion N V., Mellor JR (2010) Facilitation of Long-Term Potentiation by Muscarinic M1 Receptors Is Mediated by Inhibition of SK Channels. Neuron 68:948-963.

Cai X, Liang CW, Muralidharan S, Kao JPY, Tang CM, Thompson SM (2004) Unique roles of SK and Kv4.2 potassium channels in dendritic integration. Neuron 44:351-364.

Carnevale NT, Hines ML (2006) The NEURON book. Cambridge University Press.

Combe CL, Canavier CC, Gasparini S (2018) Intrinsic mechanisms of frequency selectivity in the proximal dendrites of CA1 pyramidal neurons. J Neurosci 38:8110-8127.

Debanne D, Gähwiler BH, Thompson SM (1998) Long-term synaptic plasticity between pairs of individual CA3 pyramidal cells in rat hippocampal slice cultures. J Physiol 507:237247.

Degro CE, Kulik A, Booker SA, Vida I (2015) Compartmental distribution of gabab receptormediated currents along the somatodendritic axis of hippocampal principal cells. Front Synaptic Neurosci 7.

Delmas P, Brown DA (2005) Pathways modulating neural KCNQ/M (Kv7) potassium channels. Nat Rev Neurosci 6:850-862.

Dennis SH, Pasqui F, Colvin EM, Sanger H, Mogg AJ, Felder CC, Broad LM, Fitzjohn SM, Isaac JTR, Mellor JR (2016) Activation of Muscarinic M1 Acetylcholine Receptors 
Induces Long-Term Potentiation in the Hippocampus. Cereb Cortex 26:414-426.

Fernández De Sevilla D, Buño W (2010) The muscarinic long-term enhancement of NMDA and AMPA receptor-mediated transmission at Schaffer collateral synapses develop through different intracellular mechanisms. J Neurosci 30:11032-11042.

Fernández de Sevilla D, Núñez A, Buño W (2020) Muscarinic Receptors, from Synaptic Plasticity to its Role in Network Activity. Neuroscience.

Giessel AJ, Sabatini BL (2010) M1 Muscarinic Receptors Boost Synaptic Potentials and Calcium Influx in Dendritic Spines by Inhibiting Postsynaptic SK Channels. Neuron 68:936-947.

Gold AE, Kesner RP (2005) The role of the CA3 subregion of the dorsal hippocampus in spatial pattern completion in the rat. Hippocampus 15:808-814.

Golding NL, Staff NP, Spruston N (2002) Dendritic spikes as a mechanism for cooperative long-term potentiation. Nature 418:326-331.

Gu Z, Yakel JL (2011) Timing-Dependent Septal Cholinergic Induction of Dynamic Hippocampal Synaptic Plasticity. Neuron 71:155-165.

Gulledge AT, Kampa BM, Stuart GJ (2005) Synaptic integration in dendritic trees. J Neurobiol 64:75-90.

Guzman SJ, Schlögl A, Frotscher M, Jonas P (2016) Synaptic mechanisms of pattern completion in the hippocampal CA3 network. Science 353:1117-1123.

Hagger-Vaughan N, Storm JF (2019) Synergy of Glutamatergic and Cholinergic Modulation

Induces Plateau Potentials in Hippocampal OLM Interneurons. Front Cell Neurosci 13. Hangya B, Ranade SP, Lorenc M, Kepecs A (2015) Central Cholinergic Neurons Are

Rapidly Recruited by Reinforcement Feedback. Cell 162:1155-1168.

Hansen N (2016) The CMA Evolution Strategy: A Tutorial.

Hasselmo ME (1999) Neuromodulation: acetylcholine and memory consolidation. Trends Cogn Sci 3:351-359.

Hasselmo ME (2006) The role of acetylcholine in learning and memory. Curr Opin Neurobiol 16:710-715.

Hasselmo ME, Wyble BP, Wallenstein G V. (1996) Encoding and retrieval of episodic memories: Role of cholinergic and GABAergic modulation in the hippocampus. Hippocampus 6:693-708.

Hemond P, Epstein D, Boley A, Migliore M, Ascoli GA, Jaffe DB (2008) Distinct classes of pyramidal cells exhibit mutually exclusive firing patterns in hippocampal area CA3b. Hippocampus 18:411-424.

Hoffman DA, Johnston D (1998) Downregulation of transient K+ channels in dendrites of hippocampal CA1 pyramidal neurons by activation of PKA and PKC. J Neurosci 18:3521-3528. 
Hopfield JJ (1982) Neural networks and physical systems with emergent collective computational abilities. Proc Natl Acad Sci U S A 79:2554-2558.

Hunt DL, Linaro D, Si B, Romani S, Spruston N (2018) A novel pyramidal cell type promotes sharp-wave synchronization in the hippocampus. Nat Neurosci 21:985-995.

Hyun JH, Eom K, Lee K-H, Bae JY, Bae YC, Kim M-H, Kim S, Ho W-K, Lee S-H (2015)

Kv1.2 mediates heterosynaptic modulation of direct cortical synaptic inputs in CA3 pyramidal cells. J Physiol 593:3617-3643.

Jȩdrzejewski-Szmek Z, Abrahao KP, Jȩdrzejewska-Szmek J, Lovinger DM, Blackwell KT (2018) Parameter Optimization Using Covariance Matrix Adaptation-Evolutionary Strategy (CMA-ES), an Approach to Investigate Differences in Channel Properties Between Neuron Subtypes. Front Neuroinform 12:47.

Kaufman AM, Geiller T, Losonczy A (2020) A Role for the Locus Coeruleus in Hippocampal CA1 Place Cell Reorganization during Spatial Reward Learning. Neuron 105:10181026.e4.

Kesner RP, Rolls ET (2015) A computational theory of hippocampal function, and tests of the theory: New developments. Neurosci Biobehav Rev 48:92-147.

Kim S, Guzman SJ, Hu H, Jonas P (2012) Active dendrites support efficient initiation of dendritic spikes in hippocampal CA3 pyramidal neurons. Nat Neurosci 15:600-606.

Larkum ME, Nevian T, Sandier M, Polsky A, Schiller J (2009) Synaptic integration in tuft dendrites of layer 5 pyramidal neurons: A new unifying principle. Science (80- ) 325:756-760.

Liu Y, Cui L, Schwarz MK, Dong Y, Schlüter OM (2017) Adrenergic Gate Release for Spike Timing-Dependent Synaptic Potentiation. Neuron 93:394-408.

Losonczy A, Makara JK, Magee JC (2008) Compartmentalized dendritic plasticity and input feature storage in neurons. Nature 452:436-441.

Lovett-Barron M, Kaifosh P, Kheirbek MA, Danielson N, Zaremba JD, Reardon TR, Turi GF, Hen R, Zemelman B V., Losonczy A (2014) Dendritic inhibition in the hippocampus supports fear learning. Science (80- ) 343:857-863.

Major G, Larkum ME, Schiller J (2013) Active properties of neocortical pyramidal neuron dendrites. Annu Rev Neurosci 36:1-24.

Makara JK, Magee JC (2013) Variable dendritic integration in hippocampal CA3 pyramidal neurons. Neuron 80:1438-1450.

Malik R, Johnston D (2017) Dendritic GIRK channels gate the integration window, plateau potentials, and induction of synaptic plasticity in dorsal but not ventral CA1 neurons. $J$ Neurosci 37:3940-3955.

Marino MJ, Rouse ST, Levey AI, Potter LT, Conn PJ (1998) Activation of the genetically defined $\mathrm{m} 1$ muscarinic receptor potentiates $\mathrm{N}$-methyl-D-aspartate (NMDA) receptor 
currents in hippocampal pyramidal cells. Proc Natl Acad Sci U S A 95:11465-11470.

Markram H, Segal M (1992) Activation of protein kinase $C$ suppresses responses to NMDA

in rat CA1 hippocampal neurones. J Physiol 457:491-501.

Marr D (1971) Simple memory: a theory for archicortex. Philos Trans R Soc Lond B Biol Sci 262:23-81.

Martinello K, Giacalone E, Migliore M, Brown DA, Shah MM (2019) The subthreshold-active KV7 current regulates neurotransmission by limiting spike-induced $\mathrm{Ca} 2+$ influx in hippocampal mossy fiber synaptic terminals. Commun Biol 2.

McClelland JL, Goddard NH (1996) Considerations arising from a complementary learning systems perspective on hippocampus and neocortex. Hippocampus 6:654-665.

Meeter M, Murre JMJ, Talamini LM (2004) Mode shifting between storage and recall based on novelty detection in oscillating hippocampal circuits. Hippocampus 14:722-741.

Mishra RK, Kim S, Guzman SJ, Jonas P (2016) Symmetric spike timing-dependent plasticity at CA3-CA3 synapses optimizes storage and recall in autoassociative networks. Nat Commun 7:11552.

Nakazawa K, Quirk MC, Chitwood RA, Watanabe M, Yeckel MF, Sun LD, Kato A, Carr CA, Johnston D, Wilson MA, Tonegawa S (2002) Requirement for hippocampal CA3 NMDA receptors in associative memory recall. Science (80- ) 297:211-218.

Papouin T, Dunphy JM, Tolman M, Dineley KT, Haydon PG (2017) Septal Cholinergic Neuromodulation Tunes the Astrocyte-Dependent Gating of Hippocampal NMDA Receptors to Wakefulness. Neuron 94:840-854.e7.

Poirazi P, Brannon T, Mel BW (2003) Arithmetic of subthreshold synaptic summation in a model CA1 pyramidal cell. Neuron 37:977-987.

Prince LY, Bacon TJ, Tigaret CM, Mellor JR (2016) Neuromodulation of the Feedforward Dentate Gyrus-CA3 Microcircuit. Front Synaptic Neurosci 8:32.

Rebola N, Carta M, Mulle C (2017) Operation and plasticity of hippocampal CA3 circuits: implications for memory encoding. Nat Rev Neurosci 18:208-220.

Rogers JL, Kesner RP (2003) Cholinergic modulation of the hippocampus during encoding and retrieval. Neurobiol Learn Mem 80:332-342.

Sohn JW, Lee D, Cho H, Lim W, Shin HS, Lee SH, Ho WK (2007) Receptor-specific inhibition of GABAB-activated $\mathrm{K}+$ currents by muscarinic and metabotropic glutamate receptors in immature rat hippocampus. J Physiol 580:411-422.

Spruston N (2008) Pyramidal neurons: Dendritic structure and synaptic integration. Nat Rev Neurosci 9:206-221.

Stuart GJ, Spruston N (2015) Dendritic integration: 60 years of progress. Nat Neurosci.

Sun J, Kapur J (2012) M-type potassium channels modulate Schaffer collateral-CA1 glutamatergic synaptic transmission. J Physiol 590:3953-3964. 
Teles-Grilo Ruivo LM, Baker KL, Conway MW, Kinsley PJ, Gilmour G, Phillips KG, Isaac JTR, Lowry JP, Mellor JR (2017) Coordinated Acetylcholine Release in Prefrontal

Cortex and Hippocampus Is Associated with Arousal and Reward on Distinct

Timescales. Cell Rep 18:905-917.

Teles-Grilo Ruivo LM, Mellor JR (2013) Cholinergic modulation of hippocampal network function. Front Synaptic Neurosci 5:2.

Treves A, Rolls ET (1994) Computational Analysis of the Role of the Hippocampus in Memory.

Tsodyks M (1999) Attractor neural network models of spatial maps in hippocampus. Hippocampus 9:481-489.

Weber JP, Andrásfalvy BK, Polito M, Magó Á, Ujfalussy BB, Makara JK (2016) Locationdependent synaptic plasticity rules by dendritic spine cooperativity. Nat Commun 7. Williams SR, Fletcher LN (2019) A Dendritic Substrate for the Cholinergic Control of Neocortical Output Neurons.

Witter MP (2007) Intrinsic and extrinsic wiring of CA3: indications for connectional heterogeneity. Learn Mem 14:705-713.

Yassa MA, Stark CEL (2011) Pattern separation in the hippocampus. Trends Neurosci 34:515-525. 